Supporting Information for

\title{
Morphological Change of Molecular Assemblies through On-Surface Chemical Reaction
}

\author{
Makoto Sakurai*, Pradyot Koley, Masakazu Aono \\ WPI-Center for Materials Nanoarchitectonics (MANA),
}

National Institute for Materials Science (NIMS). 1-1 Namiki, Tsukuba, 305-0044, Japan

Corresponding author: Makoto Sakurai, e-mail: sakurai.makoto@nims.go.jp 
(a)

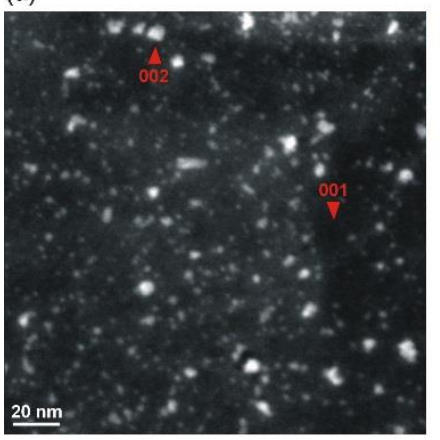

(b)

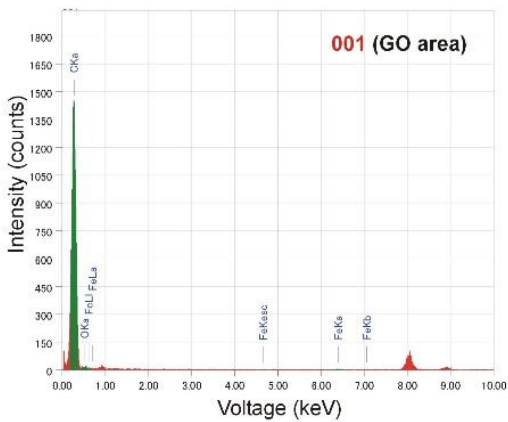

(c)

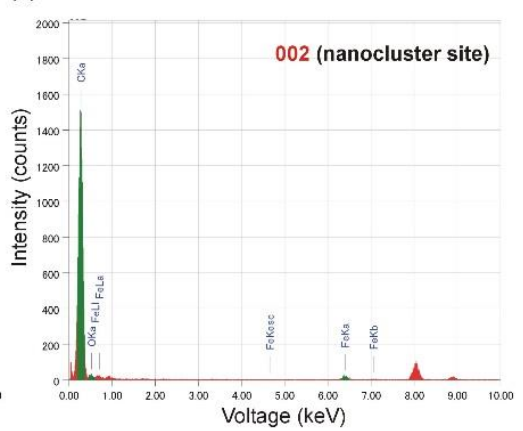

Figure S1. Scanning transmission electron microscope (STEM) image of a sheet reacted for $96 \mathrm{~h}$ without coupling agents. Local EDX spectra measured in (b) unreacted area marked as 001 and (c) nanoclusters marked as 002 in (a). Fe signals are observed only on the nanoclusters, suggesting that the nanoclusters formed from aminoferrocene molecules.
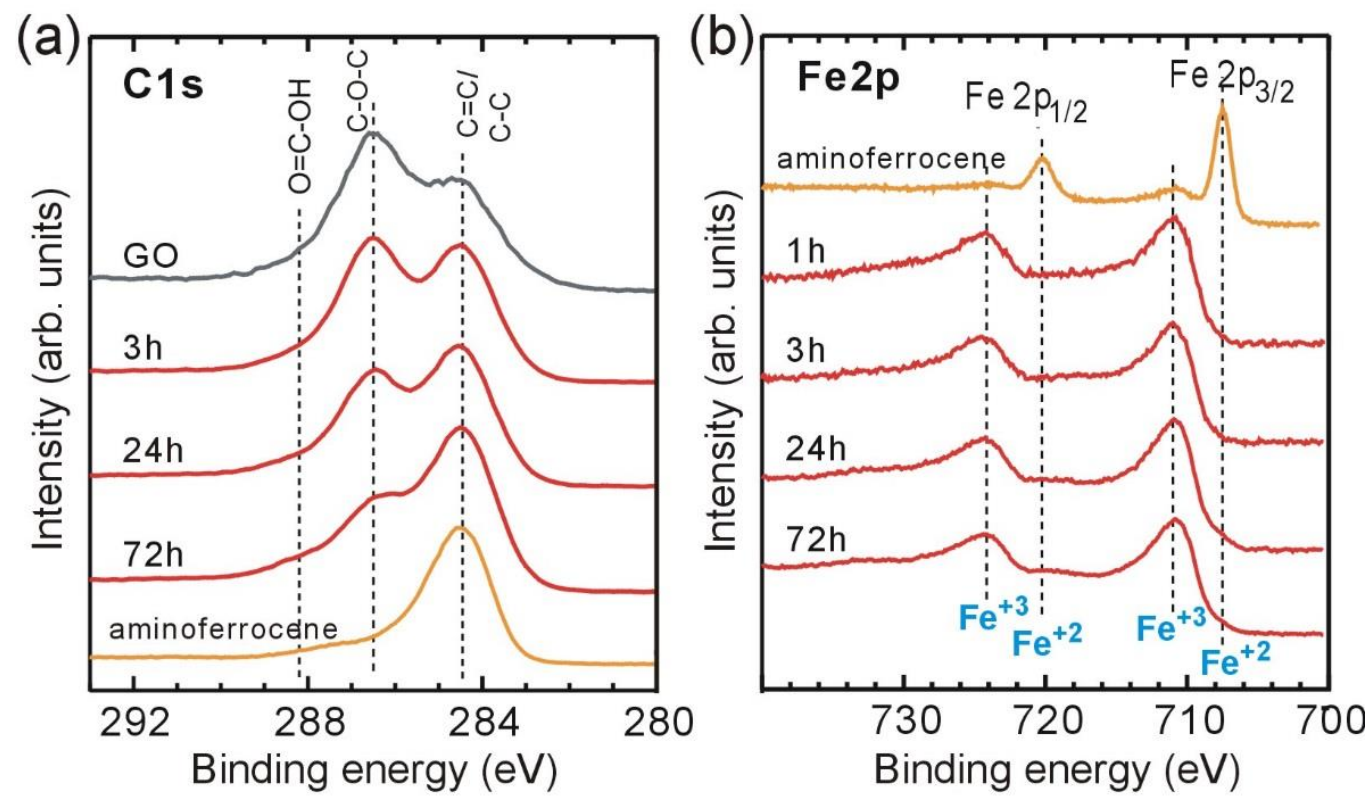

Figure S2. XPS spectra of (a) C1s and (b) Fe2p core level of pristine GO sheets (grey line), sheets reacted for $3 \mathrm{~h}, 24 \mathrm{~h}, 72 \mathrm{~h}$ with coupling agents (red line), and aminoferrocene powder (orange line). 


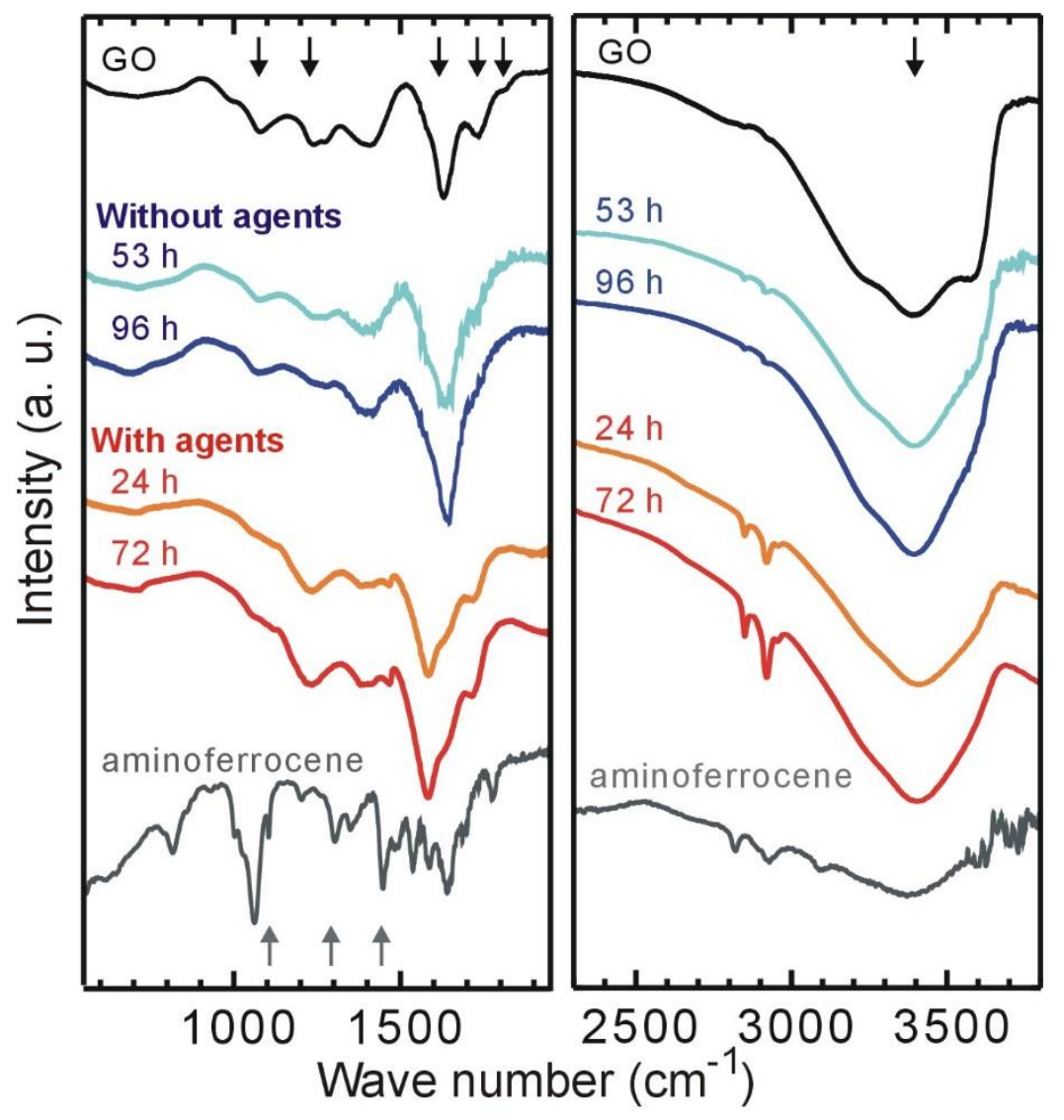

Figure S3. FT-IR spectra of pristine GO sheets (block line), GO sheets reacted for $53 \mathrm{~h}$ (light blue line), $96 \mathrm{~h}$ (purple line) without coupling agents, GO sheets reacted for $24 \mathrm{~h}$ (orange line), $72 \mathrm{~h}$ (red line) with coupling agents, and aminoferrocene powder (grey line). The spectra of pristine GO sheets illustrate the presence of ether or epoxide (1000 - 1280 $\left.\mathrm{cm}^{-1}\right), \mathrm{C}=\mathrm{C}\left(1620 \mathrm{~cm}^{-1}\right)$, carboxyl $\left(1720 \mathrm{~cm}^{-1}\right)$, carbonyl $\left(1805 \mathrm{~cm}^{-1}\right)$, hydroxyl (broad peaks at $\left.3050-3800 \mathrm{~cm}^{-1}\right)$ groups. The peaks in the spectra of aminoferrocene show vibrations of C-H at $1106 \mathrm{~cm}^{-1}, \mathrm{C}-\mathrm{N}$ at $1290 \mathrm{~cm}^{-1}, \mathrm{C}=\mathrm{C}$ at $1440 \mathrm{~cm}^{-1}$. Corresponding peaks or features are observed weakly for the sheet reacted with and without coupling agents. 
(a)

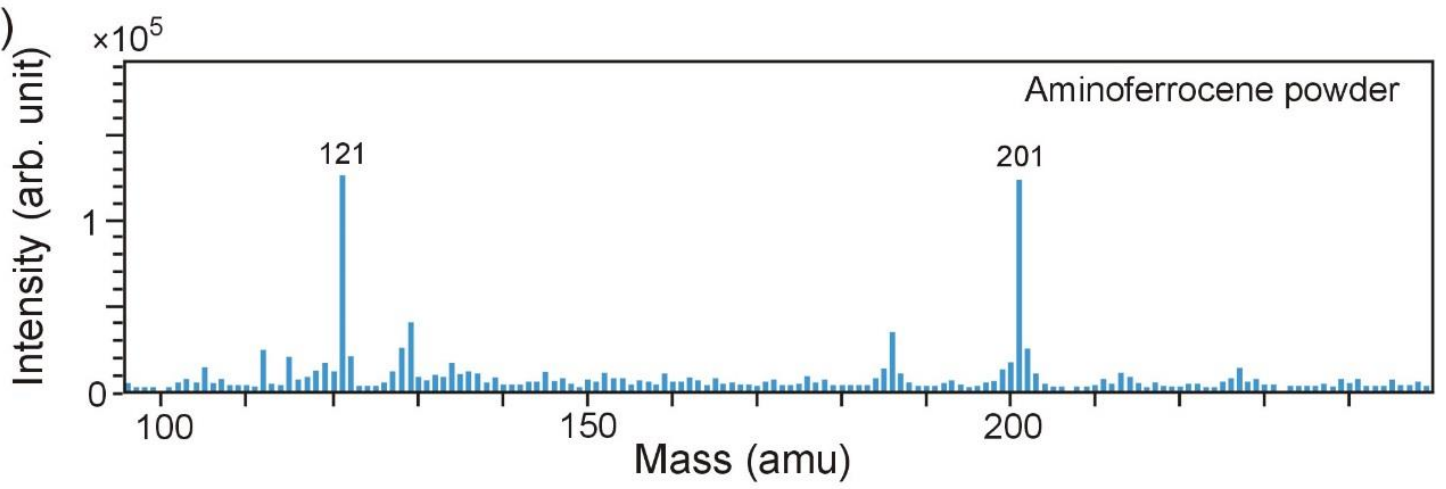

(b)

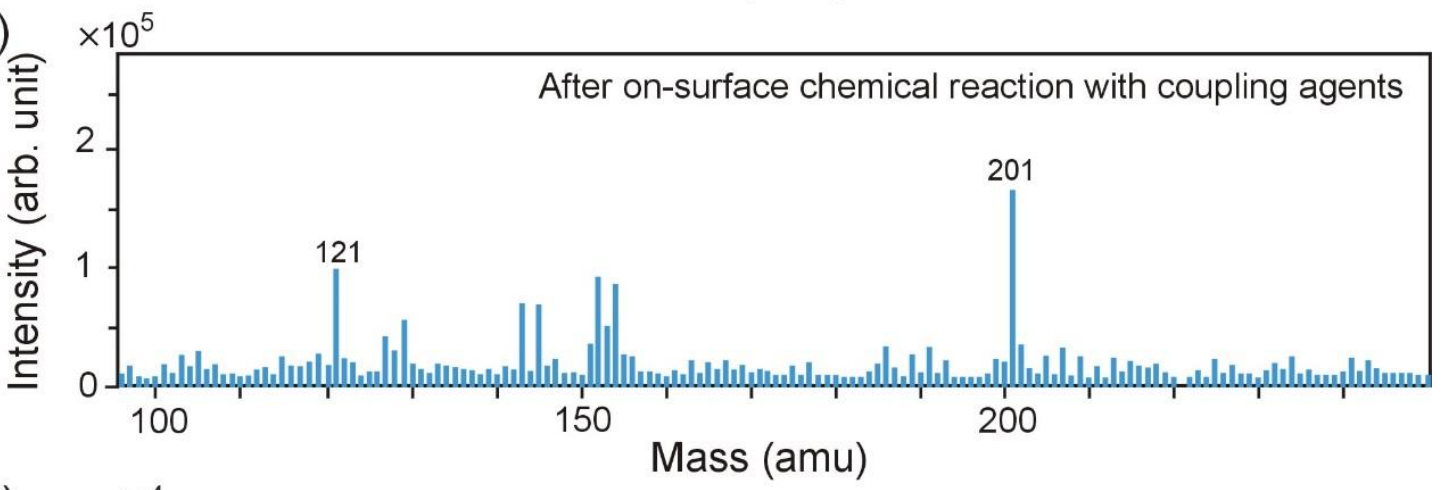

(c)

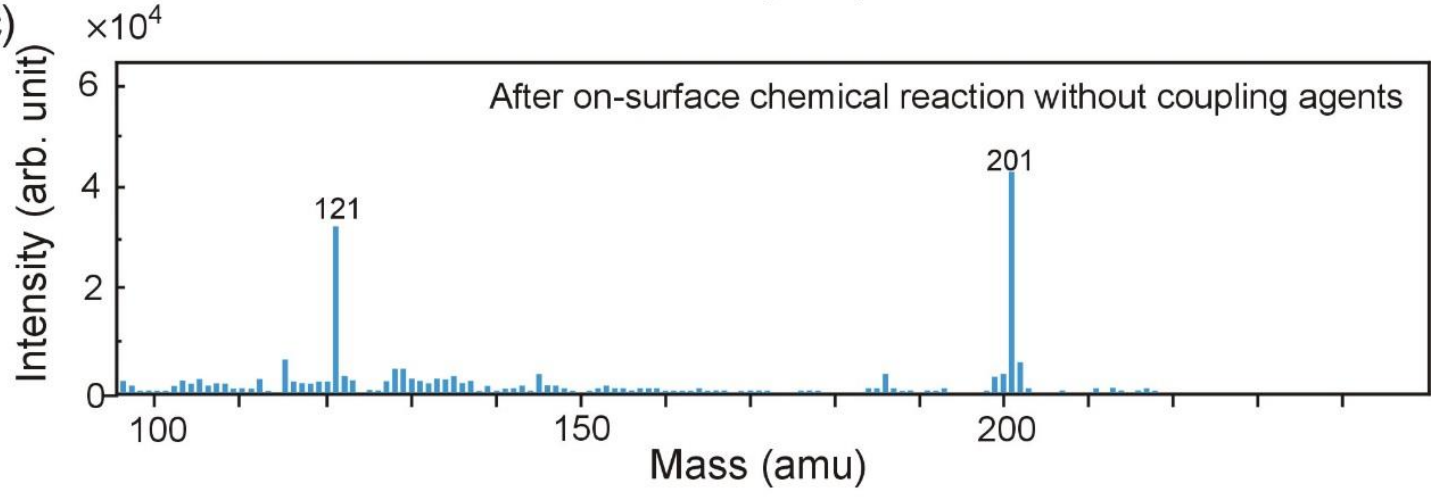

Figure S4. Mass spectroscopy of (a) aminoferrocene powder, GO sheets reacted for $72 \mathrm{~h}$ (b) with coupling agents and (c) without coupling agents. The peak at 201 $\mathrm{amu}$ in these spectra indicates that there are aminoferrocene molecules. The peaks in the smaller mass regions correspond to fragments of aminoferrocene molecules and GO sheets broken by accelerated ions bombardment. 